\title{
Da liberdade insubmissa à heresia visionária
}

\author{
Sebastiana Fadda
}

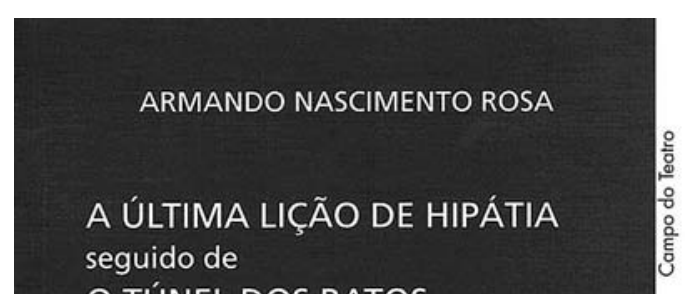

\section{O TÚNEL DOS RATOS}

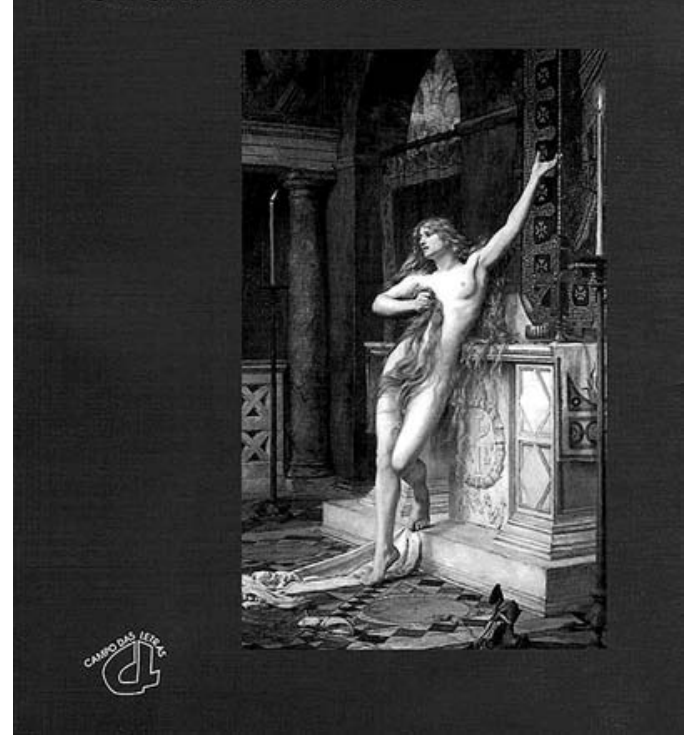

Desde 1988 - quando se estreou como critico teatral nas páginas do Diário de Notícias, de Universus-Jornal das Universidades e de 0 Jornal - que Armando Nascimento Rosa tem vindo a incrementar, com contribuições regulares, a bibliografia de e sobre teatro, disponivel no mercado editorial português. A densidade dos referentes de que todas elas se fazem portadoras, a coerência de um discurso solidamente estruturado, fundamentado na interdisciplinaridade dos saberes, bem como a qualidade da escrita e a seriedade intelectual, são alguns dos seus denominadores comuns. Este novo livro não constitui excepção e, para além de confirmar a propensão para a teatralização de uma mundividência muito peculiar, consolida a obra em geral, porque é à luz da produção anterior, inclusive da obra ensaística, que A última lição de Hipátia (redigida em 2001-2002) e 0 túnel dos ratos (redigida entre 2001 e 2004) podem e devem ser lidas.

Longe de pretender esgotar as possibilidades exegéticas, para as quais aliás o próprio dramaturgo guia os leitores nas notas preambulares das peças, é contudo

\author{
Armando Nascimento Rosa, $A$ última lição \\ de Hipátia, seguido de $O$ túnel dos ratos, \\ Porto, Campo das Letras, Colecção Campo \\ do Teatro, 2004, 315 pp.
}

oportuno salientar alguns dados significativos. Entre eles, e para os conhecedores do trabalho de Armando Nascimento Rosa talvez seja uma evidência, releva-se o facto de estarmos perante um autor que faz da escrita um lugar de confluências. Isto quer dizer que o teatrólogo informado, o teórico culto, o hermeneuta arguto e o cidadão empenhado se mantêm visíveis e vigilantes no trabalho do dramaturgo.

Quer as monografias de fôlego sobre Samuel Beckett (Falar no deserto: Estética e psicologia em Samuel Beckett, 2000) e António Patrício (As máscaras nigromantes: Uma leitura do teatro escrito de António Patrício, 2003), quer os estudos mais sucintos em torno da dramaturgia inspirada na obra de Florbela Espanca ("As máscaras de Florbela mítica na dramaturgia portuguesa", 1997), do debate entre Bertolt Brecht e Walter Benjamin ("A recusa do trágico: o teatro brechtiano visto por Benjamin", 1998), do teatro de Natália Correia ("D. João e Julieta: rostos de narciso", 1999) e das peculiaridades do tempo segundo Fernando Pessoa ("Pessoa e a visão gnóstica do tempo", 1997-2002, edição electrónica), para além de revelarem os dotes analíticos do autor em relação à obra de outros dramaturgos, apontam para aqueles universos que pertencem também a ele e à sua criação original.

Escreve Armando Nascimento Rosa no epílogo ao livro sobre Beckett: "0 crítico procede (...) a uma permanente logofagia do pensamento de outros, que com ele poderão cooperar na ensaística mise-en-scène final" (Rosa 2000: 79), assumindo o ensaio como alomorfia do discurso dramático. Mas também o inverso é admissivel. Assim, ao parafrasear-se a citação pela permuta do termo "crítico" com "dramaturgo", e procedendo a uma leve metátese sintáctica, isto é, criando a frase: "0 dramaturgo procede (...) a uma permanente logofagia do pensamento de outros, que com ele poderão cooperar na mise-enscène ensaística final", teriamos uma das chaves de leitura do universo teatral do autor. Pois se ao ensaio não é alheia uma componente dramatúrgica, o teatro filtra e encena o pensamento, num diálogo permanente entre os dois géneros, com a poesia de permeio. Nascem assim peças como Espera apócrifa (primeira versão in Actor, 1990; nova versão 2000), homenagem na morte de Beckett baseada em variações sobre o universo deste dramaturgo, 
0 túnel dos ratos, enc. José Russo Cendrev

Teatro Garcia de Resende, Évora, 2004

(Ana Meira e Rui Nuno), fot. Paulo Nuno Silva.

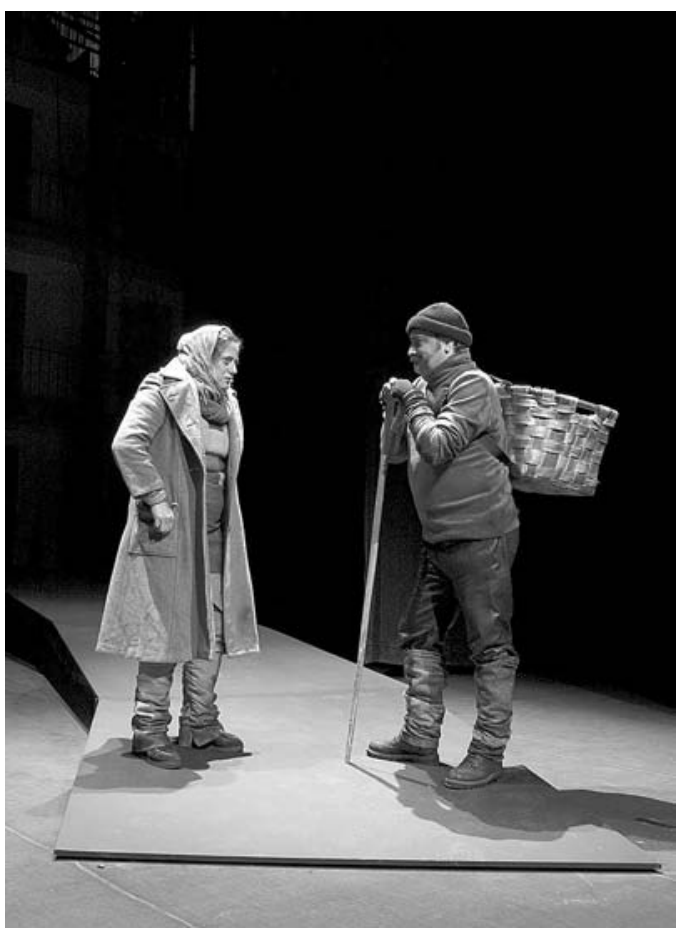

mas não só) transfigurando-a incessantemente. Tudo cabe em A última lição de Hipátia, inclusive, como o próprio título aponta, a função pedagógica do teatro. 0 palco como caixa de ressonância (ou tribuna?) para alertar as consciências, sem todavia esquecer a função lúdica, mesmo que circunscrita em grande parte aos estímulos intelectuais, imprimidos também por outras referências, comentários ou recursos:

- técnicos e formais: uma arquitectura complexa em que pelo menos uma dúzia de actores vestem as muitas máscaras de quase quatro dúzias de personagens; os interlúdios musicais, poéticos e de fantoches (talvez uma homenagem à leitura do espectáculo D. João e Julieta, baseado na peça homónima de Natália Correia, levado à cena pela Comuna em 1999, e no qual João Mota enxertou o Auto da feiticeira Cotovia);

- históricos e literários: a mitologia helénica como reservatório de símbolos que conduzem ao conhecimento do inconsciente individual e colectivo; a concepção barroca da vida como palco e do palco como metáfora da vida; o teatro dentro do teatro dentro do teatro dentro do teatro... entre o Calvino de Se uma noite de Inverno um viajante e a dramaturgia de Pirandello;

- cívicos e políticos: a paródia aos reality shows e a agonia da Gaivota tchekoviana imobilizada no crude; o assassinato duma adolescente numa escola portuguesa devido ao gesto irreflectido dum colega; a denúncia da lapidação do pensamento livre (de Hipátia, e dos perigos da perplexidade filosófica) devido à intolerância premeditada do dogma (de Cirilo, e dos abusos da mistificação religiosa). 


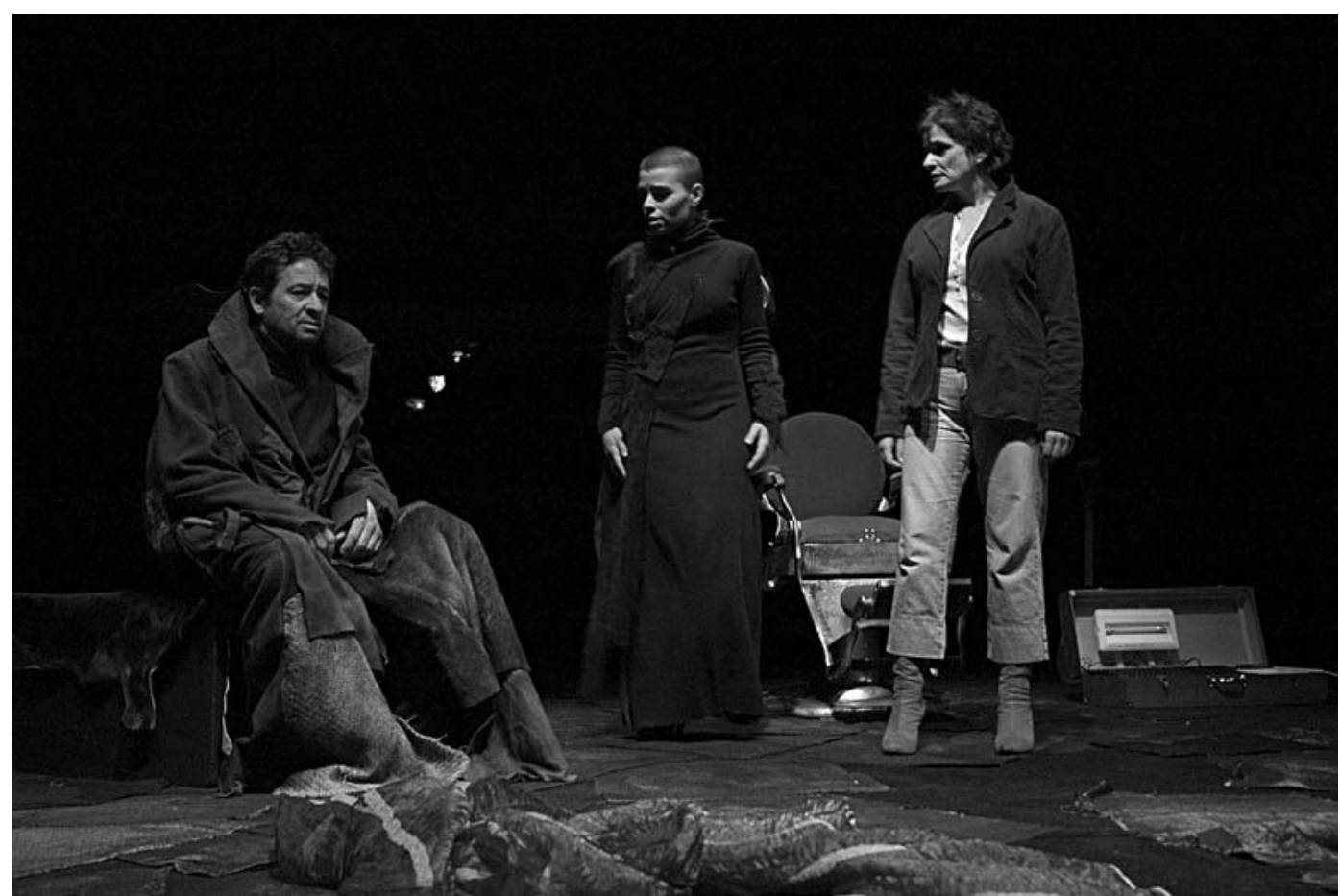

Muito mais sintética e coesa do ponto de vista dramatúrgico, por isso provavelmente mais acutilante e eficaz, a peça 0 túnel dos ratos, tal como pretendia o autor, é uma comédia de enganos com pontos de contacto - certas técnicas de construção - com a peça que a antecede. Entre outros: o uso das metáforas; a denúncia de realidades vindas da crónica coeva à redacção ou da história em sentido lato; as valências simbólicas e irónicas dos nomes; a irreverência em relação a dogmas, crenças ou falsos valores estabelecidos; a incrustação de intervalos poético-musicais. Talvez, ainda, possa ser considerada como uma possivel continuação de $A$ última lição de Hipátia, pela revitalização da filosofia platónica e gnóstica. 0 precipício que conduz da teologia (do discurso acerca da luz e do conhecimento) à teofania (à perdição nas trevas dos ícones) é assinalado pela transposição alegórica:

- no neo-Inferno dantesco, dotado do seu Virgílio como guia, em que o subterrâneo aponta para este mundo em que nos iludimos de viver na superfície e onde se apagam os Teófilos (os seguidores da luz), as Selenes (a outra face do sol, que é ainda uma forma de luz) e as Catarinas (os resíduos de pureza, já semi-negra);

- no neo-Evangelho herético, dotado do seu profeta da ratanização (evocadora da rinocerite de ionesquiana memória), em que o neo-demiurgo Virgílio se afigura como um Cristo na negativa, com os seus discipulos, o seu Paulo-Saul, as suas Madalenas e Madonnas, o seu Calvário e a sua ressurreição, mediada pela aparição duma neo-Nossa-Senhora-de-Fátima.

- na conotação grotesca e sacrílega do patronímico de uma das personagens: (Paulo) Cesto, ambíguo e duplo no significado e na categoria gramatical, unificado pela fonética, como substantivo ("cesto") tem valor instrumental e como adjectivo numérico (VI) valor simbólico; por conseguinte, e em virtude dos poderes hierárquicos que Ihe são conferidos, o caçador de ratos é ao mesmo tempo um anti-Papa na sua ascese no negativo e um anti-Pedro ministro duma nova igreja.

O túnel dos ratos é, como se percebeu, uma comédia negra, em que o elemento lúdico se torna corrosivo e a função pedagógica uma urgência. E não será apenas por sincronismo na redacção que surge na sequência de $A$ última lição de Hipátia, formando quase um díptico que deixa patentes algumas mensagens implícitas, ou moral das fábulas. Se ainda não formos ratazanas que se devoram umas às outras, talvez recusemos a lei da selva, que aniquila os mais fracos e exalta triunfadores de força duvidosa. Se a nossa morfologia for a dos morcegos, o autor esclarece que, apesar de sermos meio-ratos, temos asas para transcender os nossos limites. Finalmente, se ainda aspirarmos à liberdade, se A última lição de Hipátia nos tocar, talvez nos afaste d'O túnel dos ratos.

\section{Referências bibliográficas}

BRILHANTE, Maria João (2004), "Desvendando patricianas máscaras", Sinais de Cena, n. ․ Porto, Campo das Letras, Junho de 2004.

ROSA, Armando Nascimento (2000), Falar no deserto: Estética e psicologia em Samuel Beckett, Lisboa, Edições Cosmos, Colecção Literatura. 